\title{
A Review of the Relationship between TMT Shared Cognition and Strategic Decision Making
}

\author{
Yazhuan Liu \\ School of Business Administration, South China University of Technology, Guangzhou, China \\ Email: 1065890254@qq.com
}

How to cite this paper: Liu, Y.Z. (2017) A Review of the Relationship between TMT Shared Cognition and Strategic Decision Making. American Journal of Industrial and Business Management, 7, 1101-1110. https://doi.org/10.4236/ajibm.2017.710078

Received: September 7, 2017

Accepted: September 26, 2017

Published: September 29, 2017

Copyright $\odot 2017$ by author and Scientific Research Publishing Inc. This work is licensed under the Creative Commons Attribution International License (CC BY 4.0).

http://creativecommons.org/licenses/by/4.0/ (c) (i) Open Access

\begin{abstract}
As the main strategic decision makers, the top management team plays an important role in the development of the enterprise. High echelon theory provides a theoretical basis for the research of top management team. The original idea of the top management team is cognitive orientation, but the previous researches focus on the demographic characteristics and Heterogeneity of individual team members, ignore the social characteristics of the top management team as a team. At the same time, the results are unstable and contradictory. Furthermore, the cognitive process of top management team has always been a difficult problem in the academic circles, but has not found an effective way. Based on the upper echelons theory and shared mental model, this paper analyses systematically and summarizes the relevant research literatures, and reviews the domestic research literatures about the influence mechanism of TMT on strategic decision making, then proposes the suggestions that develop the Chinese context research and related western theories. In conclusion, the research results have great value to promote domestic scholars getting involved in this frontier research field, then keep up with the pace of international related theories development.
\end{abstract}

\section{Keywords}

Top Management Team, Shared Cognition, Shared Mental Model, Strategic Decision

\section{Introduction}

With the development of economic globalization, enterprises are facing more and more complex environment, which brings new challenges to the ability of 
enterprises to deal with various problems, and also puts forward new challenges for enterprise managers. In 1984, Hambrick and Mason put forward the theory of "Upper Echelons Theory", which provided the theoretical basis and direction for the top management team [1]. Subsequently, many researchers analyzed the related issues of TMT based on different perspectives. The domestic research of the top management team began in 2000. At first, in view of the objective demographic characteristics, domestic scholars explored the direct influence of TMT demographic characteristics and its heterogeneity, such as age, education background, occupation experience, on business strategy and performance. But those studies did not yield consistent results. Zhou Jian, Li Xiaoqing, Yang Shuai (2015) believed that TMT is the main maker of enterprise strategic decisions, and enterprise strategy formulation process is essentially a cognitive integration process of top management team [2]. Reviewing the upper echelon theory, based on TMT cognitive perspective, this theory shows different cognitive basis, values and insight as well as their operation process among TMT members influence the strategic decision and performance (Hambrick, 1984) [1]. In the existing literature, however, few scholars examined the influence of TMT on corporate strategic decision and behavior from the perspective of cognitive dimension, and ignored the intermediate process of the relationship between TMT and organizational output.

Based on the shared mental models and upper echelon theory, this article reviews and sorts out related literature, and then discusses the internal mechanism about the effect of top management team on enterprise's strategic decision from the perspective of shared cognition. Finally, we propose the future research trends, and research directions in domestic context.

\section{The Concept and Theoretical Basis of Top Management Team Shared Cognition}

\subsection{The Concept of Shared Cognition}

What is sharing? Many scholars defined the "sharing" from the point of view of team process (Cannon-Bowers \& Salas, 1993; Cole, 1991) [3] [4]. Cole (1991) believed that "sharing" have two meanings: one refers to common, such as the common knowledge and understanding to the use of company equipment, laws and regulations that team members have; the other refers to its distribution, such as team members shared tasks and duties [4]. Cannon-Bowers and Salas (1993) held that sharing means knowledge and overlap of each other expectations, rather than simply the pursuit of common consensus and views [3]. In other words, team members with their own mental model achieve the common expectations of corporate strategy and development through communication and exchange interaction.

Furthermore, Cannon-Bowers and Salas (1993) defined shared cognition as a collective belief, shared understanding [3]. Cannon-Bowers and Salas (2001) further generalized its compatible, complementary, overlapping knowledge 
owned by team members, which helps members to make more accurate expectations on team performance, and then take a collaborative work to complete the task [5]. At the same time, shared cognition is an effective index to predict team performance, which can help managers diagnose the problems existing in the team and provide solutions.

Next, how to measure it? In previous studies, scholars used a variety of different methods to measure shared cognition. Some scholars used internal rater reliability to measure shared cognition among team members. Although this method reflects the consistency of judgment among team members to some extent, there are many problems, this is, the reliability may increase with the increase of the number of evaluators, which cannot examine the influence of team size. In addition, the internal rater reliability coefficient reflects the correlation, but it cannot reflect the degree of sharing. Meanwhile, some others investigated sharing degree among members by measuring the structure and content of shared knowledge (Cannon-Bowers and Salas, 2001) [5]. But sharing knowledge is only a part of shared cognition, thus it cannot describe the sharing level of members accurately.

In general, belonging to the cognitive concept of team level, shared cognition is difficult to measure. More significantly, however, many researchers believe that the strategic decision and behavior of an enterprise must reflect the particular behavioral and psychological characteristics of its team by the communicating and interacting between team members with long-term effects. Consequently, questionnaire survey is an appropriate measuring method to ask team members some questions related to perception.

\subsection{The Theoretical Basis of Top Management Team Shared Cognition}

\subsubsection{Upper Echelons Theory}

In 1984, Hambrick and Mason first proposed the "upper echelons theory" based on the perspective of limited rationality hypothesis and cognitive psychology, the theory that the objective environment and top management team characteristics (psychological characteristics and observable characteristics) affect the strategic decision of the executive team, then the executive team will make strategic decisions consistent with their cognitive psychological model. Hambrick and Cho (1996) perfected this theory, which summarized the top management team into three aspects, namely, team composition, team process and team structure [6]. Team composition and structure mainly refer to the demographic characteristics and authority structure of top management team members. And the team operation process means coordination, communication, conflict handling and motivation among team members. Moreover, the team members' characteristics and team operation process influence strategic decision, and then affect organizational performance and strategic choice. The biggest difference from the original model is introduced the team process, which is a leap forward development of upper echelons theory. Carpenter et al. (2004) introduced the 
agency theory to integrate a more complete analysis framework, which better explain the relationship mechanism between top management team and organizational strategy, performance [7]. This analysis framework changed the previous research paradigm of TMT and corporate performance, and prompted more scholars to begin to explore the intermediate mechanism between top management team and organizational outcomes. Hambrick (2007) pointed out that the TMT demographic characteristics is the objective property of TMT, that simply analysing the impact of objective characteristics on organization behavior cannot effectively explain the role of decision maker in the decision-making process, neglected the middle top management team psychological factors [8].

In conclusion, previous studies mainly focus on "team characteristics directly affecting the organization", regarded the output process as a "black box". But to a greater extent, the authentically causal relationship depends on the cognition and mental process among top management team members (FINKELSTEIN \& HAMBRICK, 1997) [9]. However, recent studies added into the mediating factors, explore how top management team characteristics act on the middle process, such as communication, conflict and decision making, further ultimately affect the firm performance and development(Carpenter, 2004; Hambrick, 2007) [7] [8].

\subsubsection{Shared Mental Model}

Cannon-Bowers and Salas (1990) advanced the concept of shared mental model, extending mental models from individual to team level [10]. Actually shared mental model refers to the knowledge structure shared by team members, it allows the team members to form a correct understanding and expectations for the task, so as to coordinate their behavior to the team and other team members demand.

Importantly, a core idea of the shared mental model is that the team can function efficiently if members have consistent understanding and expectations of the internal and external environment, tasks, and business decisions they face. Klimoski and Mohammed (1994) considered that shared mental model is a unique mental representation, which team members collectively show consistent views and actions on team specific situations, as illustrated in Figure 1 [11]. In a word, the formation of shared mental model depends on team processes, including team communication, leadership and team management, coordination, which, in turn, facilitate communication and interaction among members, thereby contributing to team performance.

\section{Research Status of the Relationship between Top Management Team and Strategic Decision Making}

\subsection{TMT Research Stages}

The academic research on TMT comes from the "upper echelons theory", which is based on the cognitive perspective, and considers organizational performance as the result of TMT cognition. But the initial research used objective demographic 


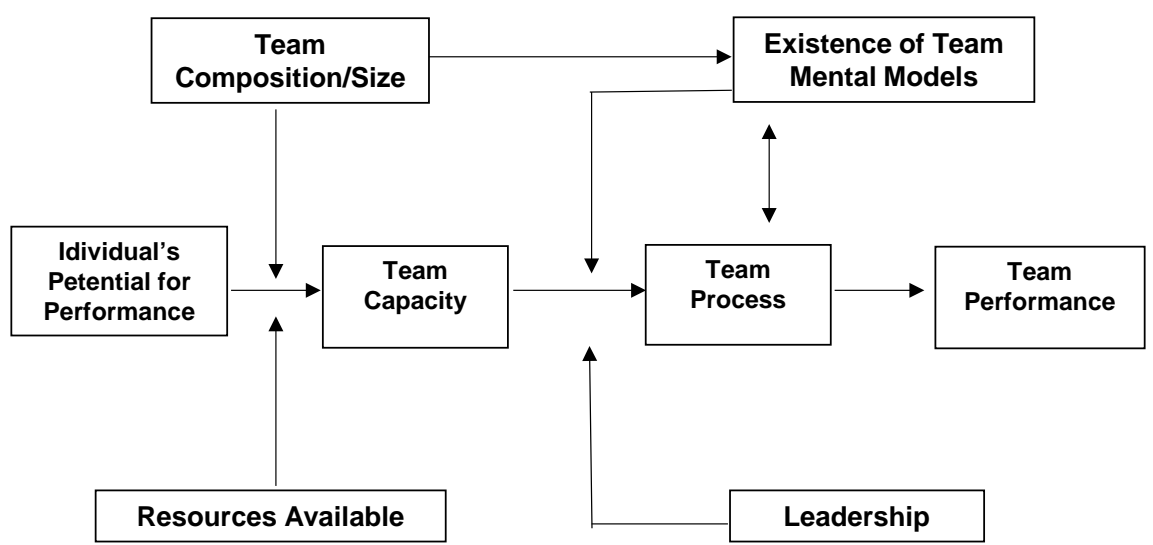

Figure 1. Framework for explaining the role of team mental models in team performance.

characteristics instead of cognition, which led to the failure of the top management team to form a consensus. Accordingly, later researchers have been working on the "black box" (Finkelstein \& Hambrick, 1997) in the top management team study [9]. In summary, research on top management team has gone through two stages.

The first stage of the study regards the TMT demographic characteristics as a substitute of cognitive characteristics. Compared with cognitive psychological factors, demographic variables are more objective, direct, lower cost and easier to measure. Accordingly, the researchers examined the impact of demographic variables, such as executive background, age, tenure, education level, on organizational strategy and performance. Actually, domestic research on top management team started relatively late, which a few simple studies were beginning to come up around 2002. Wei Liqun, Wang Zhihui (2002) held that TMT education background, occupation, experience heterogeneity have no significant effect on performance, but there is a significant positive correlation between TMT average age and performance, which may have close relationship with the Chinese network [12]. Sun Haifa and Yao Zhenhua (2006) believed that TMT size, average tenure have a positive effect on the firm's short-term performance, and TMT average education is beneficial to long-term performance, but team size is more detrimental to long-term performance [13]. In terms of TMT heterogeneity, Ouyang Hui, Zeng Deming and Zhang Yunsheng (2003) considered that the heterogeneity of TMT composition has a positive impact on organizational strategy and organizational performance [14]. Liu Jun et al. (2007) argued that the heterogeneity of TMT composition negatively influences organizational strategy and organizational performance [15].

It can be seen that the relationship between TMT demographic characteristics, heterogeneity and strategic decision-making and organizational performance is not stable or even contradictory. As a result, some scholars are trying to find new research directions and ways to better explain the stable relationship between TMT and organizational output.

Based on Hambrick and Cho (1996), Carpenter et al. (2004) theoretical 
perspectives, the second stage studies thinks that there is a intermediate mechanism between TMT characteristics and organization output, namely, team members act on the intermediate process, thereby affect the team decision-making and performance [6] [7]. On the one hand, domestic scholars begin to investigate the influence of team processes (such as communication, conflict, behavior integration) as a intermediate variable on organizational output. For instance, Ma Fuping et al. (2010) deemed that there is a significantly positive relationship between TMT heterogeneity and technological innovation performance, specifically through the intermediate mechanism of integration of behavior (communication and interaction among team members and so on), the positive impact of TMT heterogeneity on the performance of technology innovation will increase [16]. Yao Zhenhua, Sun Haifa (2011) showed that team communication frequency plays an important role, during the relationship mechanism between TMT composition characteristics and organizational performance, namely, by increasing the frequency of communication, team members increase team performance and organizational performance [17].

On the other hand, some scholars try to explain TMT studies from other perspectives, such as conflict, cohesion, attention. Wang Chongming and Liu Xuefang (2007) examined the influence of TMT cohesion on the succession performance, further found that the high TMT cohesion plays a positive role on the succession performance [18]. Through a case study of HUAWEI Company, Wu Jianzu and Bi Yusheng (2013) found enterprise internationalization strategy is a result about its executive team attention selective allocation, when the TMT focus more on technology developed and mature market, the firm tends to choose the international strategy of natural expansion [19].

\subsection{The Influence of TMT Shared Cognition on Enterprise Strategic Decision Making}

As the main makers of enterprise strategic decisions, TMT members' mental models affect the strategic decisions they make (Walsh, 1995) [20]. The increasingly complex external environment has put forward higher requirements on top management team. On the one hand, the uncertainty requires companies to build a more heterogeneous top management team, which helps to get more diverse information and resources. On the other hand, heterogeneity can lead to conflicts between members, which result in an increase in internal coordination costs and a reduction in decision-making efficiency (Xue Youzhi, Li Guodong, 2009) [21]. Most importantly, the introduction of shared cognition makes up for this problem. Specifically, during the process of making strategic decisions, top management team shared cognition can bring about multifarious views and plans from each member, meanwhile, can effectively reduce the time costs caused by conflicts that each member has a common expectation on the development of enterprises.

More concretely, Shi Shenglin and Chen Qi (2010) investigated the effect of TMT cognitive preference to the enterprise competition strategy, and agreed 
that top management team tends to analytic cognitive style in the implementation of low cost strategy of the enterprise, while TMT has two kinds of cognitive styles in the implement of differentiating strategy of the enterprise [22]. They further deemed that team is more inclined to analytic cognitive style both the implementation of low cost and differentiating strategy. Liu Hong, Wei Wenbin et al. (2012) showed that top management team cognitive conflict of private enterprise is conducive to improve the quality of decision-making, decision commitment and firm performance, simultaneously, decision commitment and decision quality play a significant intermediary role [23]. In view of cognitive need and team climate, Jiang Zexu et al. (2014) examined how top management team of state-owned enterprises improves the quality of decision-making. The result found that TMT cognitive need positively affects the enterprise decision-making quality, at the same time, team climate (team identity and team trust) has an Moderating effect on the relationship between those two [24].

It can be seen from the existing literatures, domestic studies on TMT cognition are still relatively lacking. Mostly studies base on the cognitive characteristics, while ignore the interaction process mechanism based on members' cognition. As a result, those studies are not forming a complete theoretical system, and lack of unified stable conclusion and theoretical basis. The most important problem is lack of the exploration and development of the psychological dimension that domestic scholars still use the demographic variables instead of subjective cognitive variable.

\section{Conclusion and Future Research Directions}

With the development of existing research, more and more scholars pay attention to cognitive research, however, not only domestic existing studies on team cognition are still relatively few and scattered, but also the research conclusions are not stable and consistent, even exist contradictory situation. Therefore, based on the conclusions of this study, current research limitations and the current situation in China, this paper proposes future research directions.

\subsection{Conclusion}

Based on reviewing and sorting out the domestic literature, we can draw the following conclusion, that is, shared cognition is an important factor that affects the TMT strategic decision. On the one hand, shared cognition reflects the understanding and agreement of the decision-making team towards organizational goals and strategies, which can directly affect the organizational decision they make. On the other hand, shared cognition does not mean that there is no heterogeneity and conflict, but effectively resolves conflicts through effective interaction and communication between different members, thus improves team efficiency.

The significances of this research are mainly embodied in the theoretical value and enterprise practice. In the aspect of theoretical conception, summarized the 
TMT research from the perspective of shared cognition, this study provides new ideas for future research, which facilitates to capture the team interaction factors influencing the enterprise performance. In practice, this paper provides new ideas for the construction of high-performance teams. Specifically, strengthening the knowledge sharing among team members, and improving the cognitive consistency of members to enterprise strategy further improve the efficiency of team decision-making.

The contributions of this study include the following two aspects. Firstly, introducing TMT cognition into the study of enterprise strategic decision helps to open the "black box", where TMT demographic characteristics have an unstable impact on corporate performance. To a certain extent, it helps to enrich the upper echelons theory, simultaneously develop the research category of enterprise strategic decision. Secondly, we discuss in detail the concept of shared cognition, which provide research direction for the future TMT research.

\subsection{Limitations of Existing Studies}

From the above-mentioned literature review, we can see that the existing studies have some limitations in theoretical and empirical research.

First, previous research is focused on foreign mature market economies. The basic theory of the top management team is based on the business environment and management practices of the mature market economy countries. There is an important problem, that is, the basic theory may not apply to the enterprise practice in developing countries.

Second, research variables have limitations. The domestic research variables on TMT cognition are relatively simple, and most studies are focused on the TMT demographic variables. In other words, domestic scholars seldom explain the existing problems from subjective cognitive perspective, instead, simply describe the objective characteristics. This may be due to the domestic research on TMT starting late, and existing immature applicable theory.

Third, there is a lack of interdisciplinary research. The domestic studies on TMT mostly follow the upper echelon theory, but rarely combine with other fields. For example, many foreign studies discuss the relationship between TMT and international strategic decision, while domestic related research is still scarce.

\subsection{Future Research Directions}

However, the existing research has laid a solid foundation for the follow-up research, and the future research is also gradually explored. Therefore, domestic research can be carried out in the following aspects.

First, strengthening the research of TMT cognition under different cultural environment. As is an emerging market economy, China has a cultural environment which is different from the mature market. Accordingly, exploring the cognitive research in different cultural backgrounds is more conducive to the persuasiveness and consistency of domestic research results.

Second, developing some studies about TMT cognitive characteristics, opera- 
tion process and team effectiveness in different industries. Due to domestic previous research results being inconsistent, exploring different industries studies will be more conducive to the improvement and stability of relevant management theories.

Third, future research can further search the cognitive process, and directly measure the cognition variable. Currently, most domestic studies use objective measured variables instead of cognition, which may be biased because cognition is the subjective thought formed in the human brain. Consequently, future research can be carried out from the following variables, such as cognitive conflict, shared strategic awareness, team cohesion, cognitive differences. In a word, discussing thoroughly cognitive connotation, characteristics, methods of measurement and operation process more help to explain the existing problems, and then make use of cognitive research to solve the enterprise practical issues.

\section{References}

[1] Hambrick, D. and Mason, P. (1984) Upper Echelons: The Organization as a Reflection of Its Top Managers. Academy of Management Review, 9, 193-206.

[2] Zhou, J., Li, X.Q. and Yang, S. (2015) Board Task Related Faultlines, Effort Level and Firm Value. Chinese Journal of Management, 12, 1009-1015. (In Chinese) http://www.cnki.com.cn/Article/CJFDTotal-GLXB201501009.htm

[3] Cannon-Bowers, J.A. and Salas, E. (1993) Shared Mental Models in Expert Team Decision Making. In: Castellan Jr., N.J., Ed., Individual and Group Decision Making: Current Issues, Erlbaum, Hillsdale, NJ, 221-246. https://link.springer.com/chapter/10.1007/978-3-642-21268-0_8

[4] Cole, M. (1991) Conclusion. In: Resnick, L.B., Levine, J.M. and Teasley, S.D., Eds., Perspectives on Socially Shared Cognition, American Psychological Association: Washington DC, 398-417. https://doi.org/10.1037/10096-036

[5] Cannon-Bowers, J.A. and Salas, E. (2001) Reflections on Shared Cognition. Journal of Organizational Behavior, 22, 195-202. https://doi.org/10.1002/job.82

[6] Hambrick, D.C. and Cho, T.S. (1996) The Influence of Top Management Team Heterogeneity on Firms' Competitive Moves. Administrative Science Quarterly, 41, 659-684. http://www.jstor.org/stable/2393871 https://doi.org/10.2307/2393871

[7] Carpenter, M.A., Geletkanycz, M.A. and Sanders, W.G. (2004) Upper Echelons Research Revisited: Antecedents, Elements, and Consequences of Top Management Team Composition. Journal of Management, 30, 749-778. https://doi.org/10.1016/j.jm.2004.06.001

[8] Hambrick, D.C. (2007) Upper Echelons Theory: An Update. Academy of Management Review, 32, 334-343. https://doi.org/10.5465/AMR.2007.24345254

[9] Finkelstein, S. and Hambrick, D.C. (1997) Strategic Leadership Top Executives and Their Effects on Organination. Academy of Management Review, 22, 802-805.

[10] Cannon-Bowers, J.A. and Salas, E. (1990) Cognitive Psychology and Team Training: Shared Mental Model in Complex System. The 5 th Annual Conference of the Society for Industrial Organizational Psychology, Miami, FL, 1-4. http://citeseerx.ist.psu.edu/showciting?cid=2451472

[11] Klimoski, R. and Mohammed, S. (1994) Team Mental Model: Construct or Metaphor? Journal of Management, 20, 403-437. 
https://doi.org/10.1177/014920639402000206

[12] Wei, L. and Wang, Z. (2002) Empirical Study on the Relationship between Characteristics of Top Management Teams and Firm Performance of Chinese Business. Nankai Business Review, 4, 16-22. http://www.cnki.com.cn/Article/CJFDTotal-LKGP200204004.htm

[13] Sun, H., Yao, Z. and Yan, M. (2006) The Effect of Demographic Traits of Top Management Team on Performance of Textile and Information Technology Corpotations. Nankai Business Review, 6, 61-67. http://www.cnki.com.cn/Article/CJFDTotal-LKGP200606013.htm

[14] Hui, O., Zeng, D. and Zhang, Y. (2003) The Impact of TMT Heterogeneity on Corporate Performance in an International Competitive Environment. The Journal of Quantitative \& Technical Economics, 12, 125-129. http://www.cnki.net/kcms/doi/10.13653/j.cnki.jqte.2003.12.032.html

[15] Liu, J., Li, Y. and Fu, P.P. (2007) An Empirical Studies: China TMTs Members' Value Congruence and Conflicts and Team Performances. Chinese Journal of management, 5, 644-653.

http://www.cnki.com.cn/Article/CJFDTotal-GLXB200705021.htm

[16] Ma, F. and Guo, X. (2010) An Study on Correlation between Heterogeneity of TMT and Technological Innovation Performance-The Moderating Role of Behavioral Integration of TMT. Science of Science and Management of $S \& T, 12,186-191$. http://www.cnki.com.cn/Article/CJFDTotal-KXXG201012029.htm

[17] Yao, Z. and Sun, H. (2011) The Relationship between Top Management Teams' Composition, Communication Frequency and Organizational Performance. Soft Science, 6, 64-68, 75. http://www.cnki.com.cn/Article/CJFDTotal-XUXI201106016.htm

[18] Wang, C. and Liu, X. (2007) An Empirical Study of the Influence of TMT Cohesion on the Succession Performance of Amily Firms. Management World, 10, 84-98. http://www.cnki.com.cn/Article/CJFDTOTAL-GLSJ200710012.htm

[19] Wu, J. and Bi, Y. (2013) TMT Attention Distribution and International Expansion Strategy Choice: A Case Study on Huawei Technologies Ltd. Chinese Journal of Management, 9, 1268-1274. http://d.wanfangdata.com.cn/Periodical/glxb201309003

[20] Walsh, J.P. (1995) Managerial and Organizational Cognition: Notes from a Trip Down Memory Lane. Organization Science, 6, 280-321. https://doi.org/10.1287/orsc.6.3.280

[21] Xue, Y. and Li, G. (2009) Empirical Study of Internationalization Strategy Implementation and Top Management Team Composition. Chinese Journal of Management, 11, 1478-1485.

http://www.cnki.com.cn/Article/CJFDTOTAL-GLXB200911009.htm

[22] Shi, S. and Chen, Q. (2010) An Empirical Study of Relationship between TMT Cognition Style and Competitive Strategy. Science of Science and Management of S \& T, 12, 147-153. http://www.cnki.com.cn/Article/CJFDTOTAL-KXXG201012024.htm

[23] Liu, H. Wei, W. and Shen, Z. (2012) An Empirical Study on the Influence of TMT Cognitive Conflict on Firm Performance. Productivity Research, 9, 213-215. http://www.cnki.net/kcms/doi/10.19374/j.cnki.14-1145/f.2012.09.081.html

[24] Jiang, Z., Gao, J. and Yang, Y. (2014) How Does the Top Management Team in State-Owned Enterprises Improve the Quality of Decision Making? Based on the Interaction Effects of Cognitive Demand and Team Climate. Journal of Chinese Academy of Governance, 1, 59-63.

http://www.cnki.net/kcms/doi/10.14063/j.cnki.1008-9314.2014.01.021.html 